\title{
ROMANIAN
}

NEUROSURGERY

Vol. XXXIV | No. 4 December 2020

Multilocular hydrocephalus

Harold Vasquez,

Ezequiel García-Ballestas, Luis Rafael Moscote-Salazar,

Sergio A Serrato,

William A Florez,

Amit Agrawal 


\section{Multilocular hydrocephalus}

\section{Harold Vasquez ${ }^{1,5}$, Ezequiel García-Ballestas ${ }^{2}$, Luis Rafael Moscote-Salazar ${ }^{3}$, Sergio A Serrato ${ }^{4}$, William A Florez ${ }^{5}$, Amit Agrawal ${ }^{6}$}

${ }^{1}$ Facultad de Ciencias de la Salud, Universidad del Sinu Elias

Bechara Zainum, Cartagena de Indias, COLOMBIA

${ }^{2}$ Center for Biomedical Research (CIB). Faculty of Medicine -

University of Cartagena, COLOMBIA

3 Neurosurgeon. Critical Care. Center for Biomedical Research (CIB).

Director of Research Line Cartagena Neurotrauma Research Group.

Faculty of Medicine - University of Cartagena, COLOMBIA

4 Uros Clinic, Neiva, ColomBIA

5 Latin-American council of neurointensivism - ClaNi, Cartagena,

COLOMBIA

${ }^{6}$ Department of Neurosurgery, All India Institute of Medical

Sciences, Saket Nagar, Madhya Pradesh, INDIA

\section{ABSTRACT}

Multilocular hydrocephalus is an entity that occurs relatively frequently in neurosurgical practice. We are present an editorial letter with a mini-review of the pathophysiology, surgical, and medical treatment.

Multiloculated hydrocephalus ( $\mathrm{MH}$ ) has also been termed as a multiseptate hydrocephalus, polycystic hydrocephalus, interventricular septum and can be unilocular or multiloculated. ${ }^{5,6,9} \mathrm{MH}$ is characterized by the presence of septations or obstructions within the normal ventricular system, leading to cerebrospinal fluid (CSF) accumulation due to a lack of communication between ventricles ${ }^{4,6,8,10,11}$. Although the etiology and pathogenesis not clearly known, the presence of septations has been considered to be caused by a fibrous adhesion within the ventricles or by inflammation leading to sub ependymal gliosis leading to glial bumps and septations leading to Ventricular obstruction ${ }^{4,8,9}$.

Many etiological factors have been shown to associate with multiloculated hydrocephalus such as many intracranial processes as infection, intracranial hemorrhage, bacterial or fungal meningitis, congenital malformations, birth trauma, tumors, intracranial surgery, among others $2,6,8,10,11$

Histologically, ventricular septum it is origins from a glial protrusion

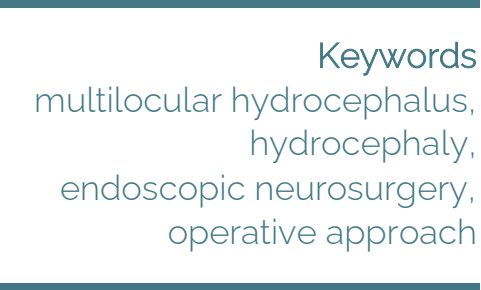

$\triangle$

Corresponding author: William A Florez

Latin-American council of neurointensivism - ClaNi, Cartagena, Colombia

william-florez@hotmail.com

Copyright and usage. This is an Open Access article distributed under the terms of the Creative commons Attribution Non-Commercial No Commons Attribution Non-Commercial No
Derivatives License (https://creativecommons Derivatives License (https://creativecommons
org/licenses/by-nc-nd/4.0/) which permits noncommercial re-use, distribution, and reproduction in any medium, provided the original work is unaltered and is properly cited.

The written permission of the Romanian Society of Neurosurgery must be obtained for commercial re-use or in order to create a derivative work.

ISSN online 2344-4959 (C) Romanian Society of Neurosurgery

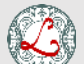

First published

London Academic Publishing www.lapub.co.uk 
in ventricles ${ }^{4}$. The clinical presentation is determined by the most frequent manifestations of complicated hydrocephalus, such as: enlargement of the head, convulsions, neurological impairment, sign of the setting sun (inability to look upwards, observed with higher frequency in infants), headache or mental retardation ${ }^{3,7}$. On the other hand, in the worst scenario, many patients may have the intracranial pressure (ICP) increased, presented as a consequence of the expansion or enlargement of the ventricles (ventriculomegaly) 3,10. Computed tomography (CT) and magnetic resonance imaging (MRI) allow visualization of the multiple cavities with CSF and irregular dilations with multiple septations (Figure -1$)^{2,4,9,10}$. the complications may be obtained by catheters and interventions to relief the symptoms caused by raised intracranial pressure, however, the primary goal is to establish communication between existing compartments and thereby achieve the diversion of the CSF 8,10

Treatment seeks to restore communication between isolated intraventricular compartments, in order to create a single cavity and implement a single bypass ${ }^{11}$. Treatment options include placement of multiple bypass systems, endoscopic fenestration of localized compartments, septostomy, third endoscopic ventriculostomy, stereotactic aspiration, or craniotomy for the microsurgical fenestration of localized compartments or combination of several surgical principles. ${ }^{2,3,4,10}$ This mentioned open surgical and endoscopic approach effective at improving adequate function of CSF derivation. Furthermore, endoscopic techniques have the advantage in decrease time of surgery, need of transfusion and length hospital stay ${ }^{1}$.The craniotomy and open surgical approach show a better success rate in severity and/or refractory chases ${ }^{1,2}$

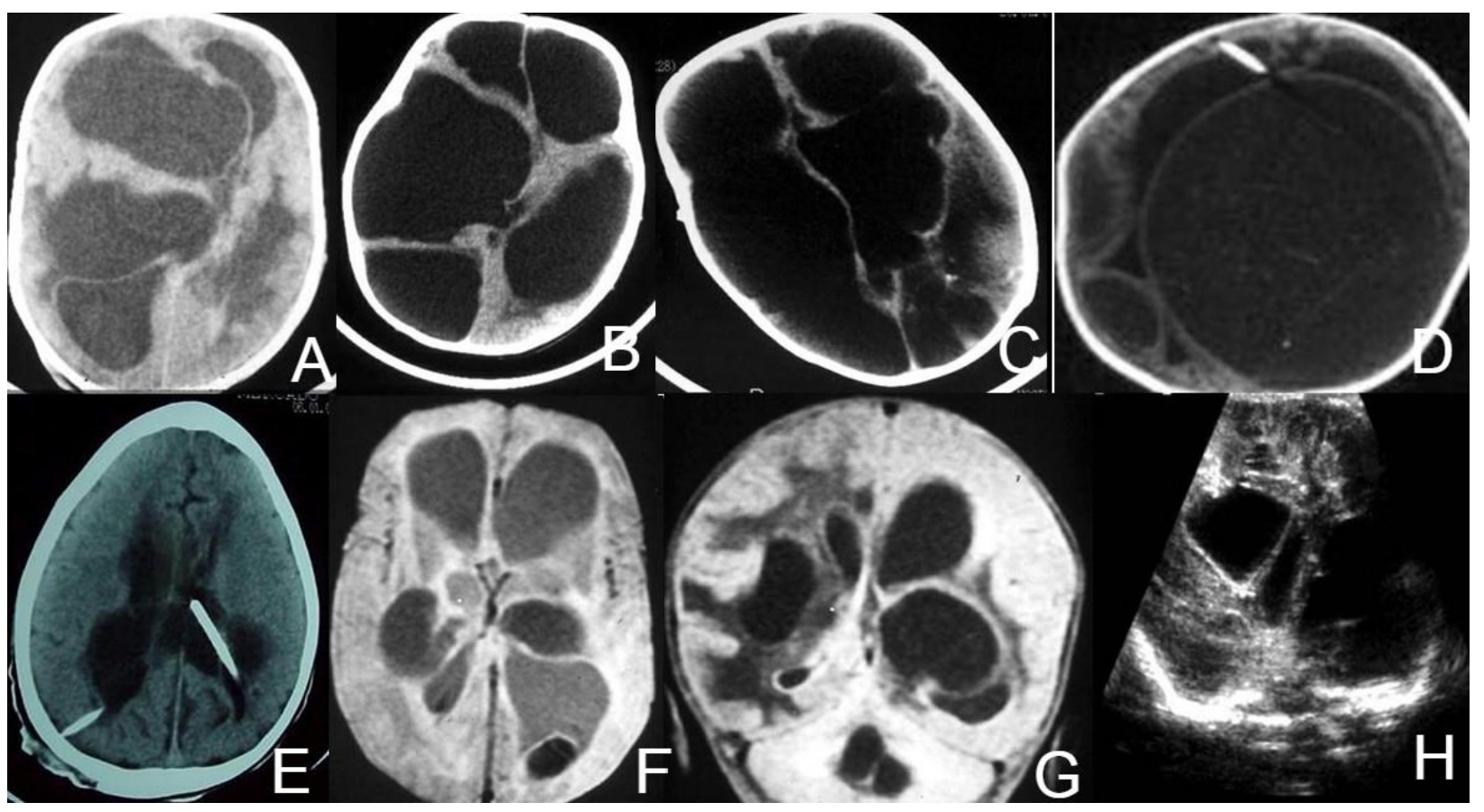

Figure 1. CT scan (A-E), MRI ( $F$ and G) and USG images showing characteristic imaging appearance of multiloculated hydrocephalus i.e., dilated ventricle and multiple septations.

\section{REFERENCES}

1. Akbari SHA, Holekamp TF, Murphy TM, Mercer D, Leonard JR, Smyth MD, et al. Surgical management of complex multiloculated hydrocephalus in infants and children. Child's Nerv Syst. 2015;31(2):243-9.

2. Andresen $\mathrm{M}$, Juhler M. Multiloculated hydrocephalus: a review of current problems in classification and treatment. Child's nervous system: ChNS : official journal of the International Society for Pediatric Neurosurgery 2012;28:357-362.

3. Chamilos C, Sgouros S. Intrauterine grade IV intraventricular hemorrhage in a full-term infant leading to hydrocephalus. Child's nervous system: ChNS: official journal of the International Society for Pediatric Neurosurgery 2013; 29:861-865.

4. El-Ghandour NM. Endoscopic cyst fenestration in the treatment of multiloculated hydrocephalus in children. 
Journal of neurosurgery Pediatrics 2008;1:217-222.

5. Eshra MA. Endoscopic management of septated, multiloculated hydrocephalus. Alexandria Journal of Medicine 2014;50:123-126.

6. Jamjoom AB, Mohammed AA, al-Boukai A, Jamjoom ZA, Rahman N, Jamjoom HT. Multiloculated hydrocephalus related to cerebrospinal fluid shunt infection. Acta neurochirurgica 1996;138:714-719.

7. Kirkpatrick M, Engleman H, Minns RA. Symptoms and signs of progressive hydrocephalus. Archives of disease in childhood 1989;64:124-128.

8. Lee $\mathrm{YH}$, Kwon YS, Yang KH. Multiloculated Hydrocephalus: Open Craniotomy or Endoscopy? J Korean Neurosurg Soc 2017;60:301-305.

9. Lewis Al, Keiper GL, Jr., Crone KR. Endoscopic treatment of loculated hydrocephalus. Journal of neurosurgery 1995;82:780-785.
10. Sandberg DI, McComb JG, Krieger MD. Craniotomy for fenestration of multiloculated hydrocephalus in pediatric patients. Neurosurgery 2005;57:100-106; discussion 100-106.

11. Zuccaro G, Ramos JG. Multiloculated hydrocephalus. Child's nervous system : ChNS : official journal of the International Society for Pediatric Neurosurgery 2011;27:1609-1619. 